\title{
The Use of a Thermistor for Detecting Eluent Fronts in Liquid-Solid Chromatography
}

\author{
Gaylon S. Ross
}

\author{
(July 24, 1961)
}

\begin{abstract}
The adsorption-desorption phenomenon which occurs when a multicomponent liquid is forced through a column of solid adsorbent is accompanied by an evolution of heat. The resulting temperature change occurring within the column may be monitored and correlated with the compositional changes occurring in the liquid phase. The construction and use of thermistor sensing cells is described. These cells are an integral part of the column, and they are maintained at appropriate temperatures by either constant temperature, liquidcirculating baths or by transistorized temperature controllers. Both methods of temperature control are described, and various applications of the cells are discussed.
\end{abstract}

\section{Introduction}

As part of a study of liquid-solid chromatography, it was desirable to develop means which would allow the process to be observed at various positions down the column length. The adsorption of a liquid upon the solid adsorbent causes an evolution of heat, and the displacement of this adsorbed liquid by a more tenaciously adsorbed liquid produces a further evolution of heat. The heats of preferential sorption upon a wide variety of solid sorbents have been determined using a calorimeter of simple design. ${ }^{1}$ An application of this principle to observe the heat from the adsorption-desorption process as it takes place in the chromatographic column is described herein.

A small thermistor, embedded in the column packing, is used to detect the temperature changes produced by the adsorption-desorption process. Since the magnitude of this temperature change may vary from, at most, a few degrees to as little as a tenth of a degree, the portion of the column containing the thermistor must be kept at nearly constant temperature if good sensitivity is desired. This is achieved by a constant temperature, circulating bath or by electrical resistance heating with a suitable controller. The thermistor, the brass block which houses and supports the thermistor, and the necessary heating jackets are referred to herein as the "cell". These cells provide an in situ analytical tool for sensing and recording the changes in column temperature which result from the heat generated by adsorption. The inner diameter of the cell is made the same as the inner diameter of the column; the packing is continuous through both the cells and the column; and there are no large obstructions to the liquid flow. The cells, described in detail later, are connected to the glass column by means

1 A. Groszek, J. Chromatog. 3, 454, (1960). of a kovar-glass seal. As many cells as are desired may be placed at predetermined positions down the column length, and the column behavior may be monitored without loss of material and without disturbing the column continuity. Not only can the progress of the separation, as it occurs on the column, be observed, but the collection of fractions can be accomplished automatically, and qualitative estimates of the differential heats of adsorption can be obtained.

\section{Apparatus}

Several different types of cells have been constructed. While they differ, depending on their intended use, they are similar to the one shown in figure 1. This cell is made in two sections, which are electrically insulated from each other by means of a Teflon gasket. A glass-coated bead thermistor $\left(2,000\right.$ ohms at $\left.20^{\circ} \mathrm{C}\right)$ is centered between the two sections, as shown (D). It has been found that the 2,000-ohm thermistors give adequate response when used as one arm of a balanced-arm Wheatstone bridge. The platinum-iridium leads of the thermistor electrically bridge the two brass cell members. These sections are held together by springloading, which maintains a liquid-tight seal despite temperature changes. The column is packed with solid adsorbent so that it is continuous throughout the total length of the column, including the cell sections. The inner diameter is the same as that of the column so that the chromatographic separation may be recorded without disturbing the advancing liquid fronts. Figure 2 is a schematic representation of a typical column showing two different types of cells in a single column. The upper cell is the same as that shown in figure 1 . In the upper cell, figure 2 , water maintained at a constant temperature by an auxiliary water bath is circulated through a water jacket. For the lower cell, which is of one-piece design, an electricallyheated copper block is substituted for the water 


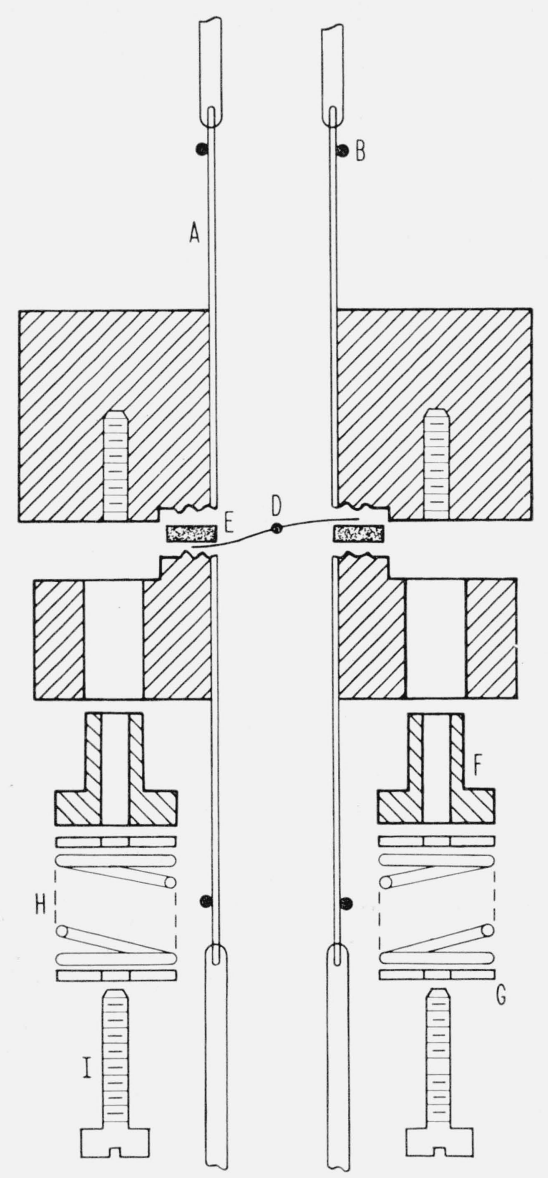

Figure 1. Temperature sensing cell.

A. Kovar to Pyrex graded seal

B. Wire soldered to kovar, used as electrical contact

C. Brass-cell body

D. Thermistor bead in place in packed column (bead, 0.01 -in. diam)

$\mathrm{E}$. Teflon gasket

E. Teflon gasket

F. Kel-F insulat

G. Brass w

I. Screws holding cell halves together

jacket. The block is maintained at constant temperature by the transistorized proportionating controller ${ }^{2}$ shown in figure 3.

\section{Experimental Procedure}

An example of the chromatogram obtained with this apparatus is given in figure 4 . The test mixture contained equal volumes of $n$-heptane, carbon tetrachloride, and benzene. The mixture was chosen to illustrate different degrees of compound separation. Ten milliliters of this mixture were poured onto the top of a silica gel (28-200 mesh) packed column. The column was $6 \mathrm{ft}$ long and $3 / 8$ in. in diam. The cell was maintained at $30{ }^{\circ} \mathrm{C}$. Ethyl alcohol was used to elute the test mixture.

2 The author is indebted to Malcolm Morse of the Instrumentation Division for designing this low-cost controller and for the privilege of including it in this paper. The instrument provides control of $\pm 0.02{ }^{\circ} \mathrm{C}$ for several hours at an operating temperature of $60^{\circ} \mathrm{C}$.
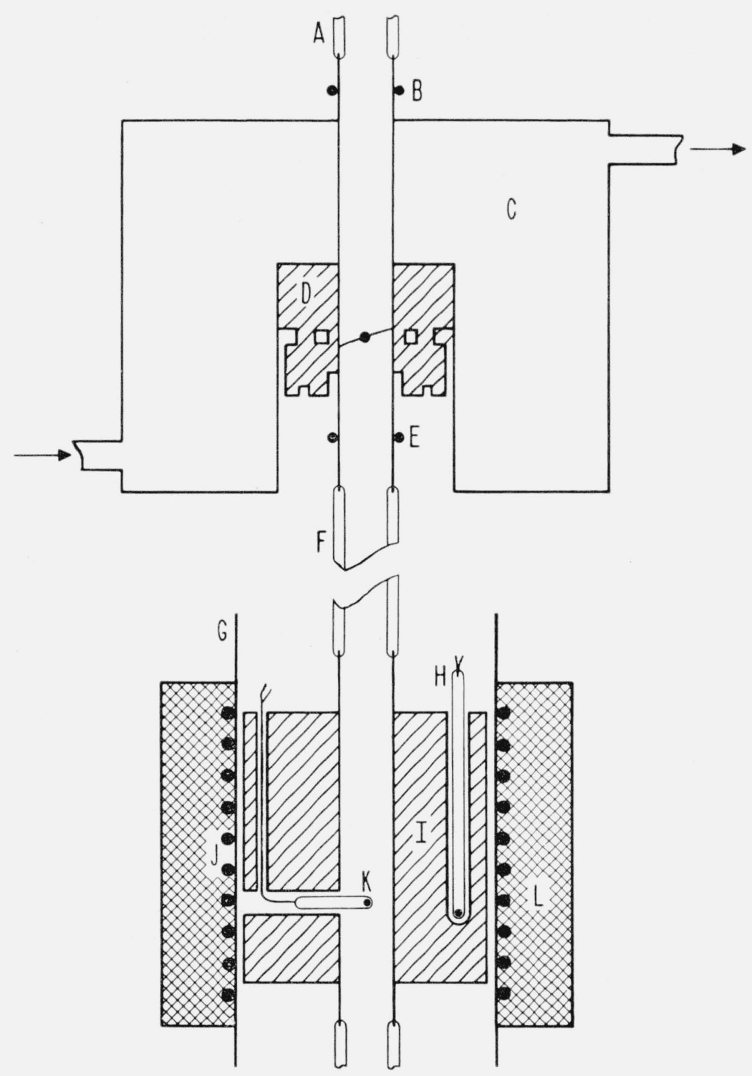

Figure 2. Typical packed column.

Two cells are shown. The top one is a two-piece cell being thermostated by a constant-temperature circulating liquid. The lower cell is a one-piecelcell being thermostated by an electrically heated jacket which is maintainediat constant temperature.

A. Kovar to Pyrex graded seal

B. Wire serving as electrical contact

C. Jacket containing thermostating liquid

D. Cell as shown in fig.

E. Electrical contact

F. Kovar to Pyrex graded seals

G. Brass tubing

H. Control thermistor

I. One-piece brass cel

J. Electrical heating wire

K. Sensing thermistor (glass rod, 0.08-in. diam, 1/2-in. length)

Glass insulation.

The cell was placed at the exit end of the column so that the refractive indices of the eluent could be compared directly with the recorded temperature variations. However, it could have been placed in any position down the length of the column, or several cells could have been used in series so as to follow the separation process. When a signal attenuation of 30 times was used, the record shown in figure 4 was obtained by using a $10-\mathrm{mv}$, potentiometric strip-chart recorder. The refractive index curve (dotted) was obtained by measuring successive $0.5-\mathrm{ml}$ portions of the sample as it emerged from the bottom of the cell. Accumulative error in measuring the volume of these cuts is probably responsible for the phase shift between the two curves. 


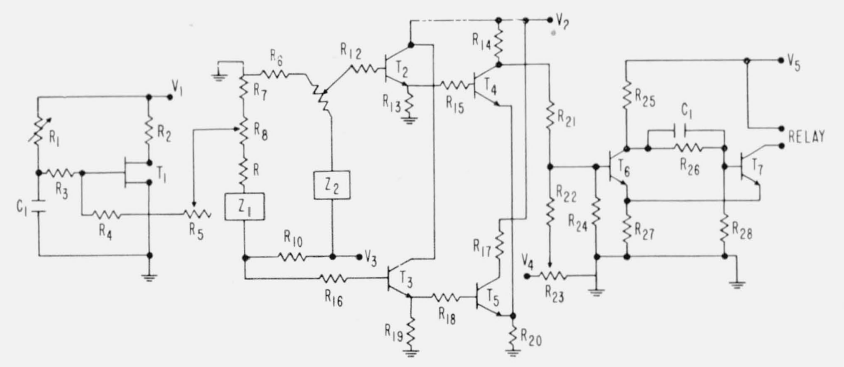

FIguRE 3. Wiring diagram for transistorized proportionating controller.

Resistance $\left(\mathrm{R}_{\mathrm{i}}\right)$, 1/2 watt unless otherwise specified

$\begin{array}{rl}1 & 10 \mathrm{~K} \\ 2 & 470 \mathrm{ohm} \\ 3 & 10 \mathrm{ohm}, 1 \text { watt } \\ 4 & 1 \mathrm{~K} \\ 5 & 10 \mathrm{~K} \\ 6 & 800 \mathrm{ohm} \\ 7 & 100 \mathrm{ohm} \\ 8 & 50 \mathrm{ohm} \\ 9 & 100 \mathrm{ohm} \\ 10 & 1050 \mathrm{ohm} \\ 11 & 500 \mathrm{ohm} \\ 12 & 470 \mathrm{ohm} \\ 13 & 1 \mathrm{~K} \\ 14 & 1 \mathrm{~K}\end{array}$

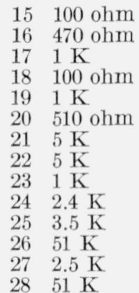

Capacitors $\left(\mathrm{C}_{\mathrm{i}}\right)$

$12,000 \mathrm{mfd}$

$210,000 \mathrm{mfd}$

Transistors $\left(\mathrm{T}_{\mathrm{i}}\right)$

$1 \quad 2 \mathrm{~N} 489,2 \mathrm{~N} 490$,

$\begin{array}{ll}2 & 2 \mathrm{~N} 377 \\ 3 & 2 \mathrm{~N} 377\end{array}$

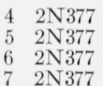

Voltage sources (batteries $\mathrm{B}_{\mathrm{i}}$ )

$\begin{array}{ll}1+221 / 2 \mathrm{~V} & 4+6 \mathrm{~V} \\ 2 & 5+9 \mathrm{v}\end{array}$

$2+9 \mathrm{v}$
$3+6 \mathrm{v}$

Thermistors $\left(Z_{i}\right)$

1, $2 \quad 800-$ ohm thermistors at operating temperature.

Relay

Sigma, 7A OY 3,500 SD-SIL. 3,500-ohm dual coils, polarized.

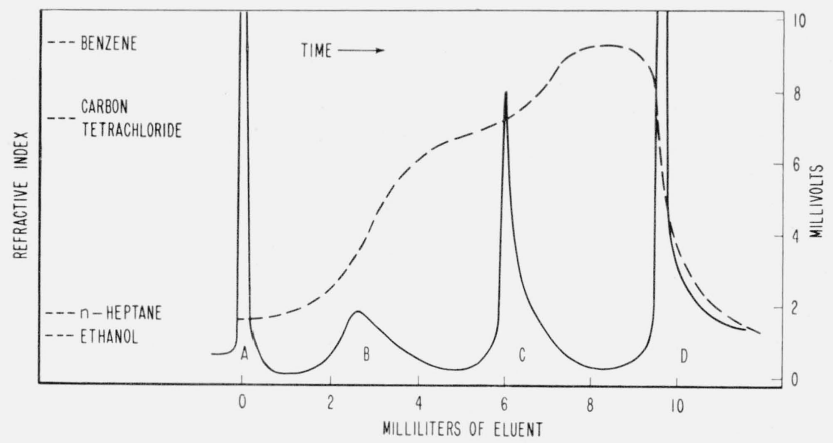

Figure 4. Recorded chromatograph.

Refractive index plot is shown as dashed curve. Refractive indices of the pure components are shown at left of figure. "A" is the peak due to the heat of adsorption of $n$-heptane; "B" the peak due to carbon tetrachloride, "C" that due to benzene and "D"' that due to ethanol.

\section{Discussion}

This cell has been used with several different test mixtures. In all cases distinct peaks were obtained when the refractive indices showed that a separation of the components had taken place in the column. In general, a broad peak is indicative of incomplete separation, and the amount of tailing appears to be inversely proportional to the degree of separation.

The height and broadness of the peaks are influenced by many factors such as degree of resolution, flow rate, thermal conductivity, thermal diffusion, cell temperature, etc. Under constant column head-pressure, the flow rate is nearly constant, and the height and area under the peaks give valuable information concerning the relative differential heats of adsorption and quantity of material.

The cell may be used to actuate an automatic fraction collector. This can be done by using an adjustable limit-switch on the recorder to rotate the fraction collecting table when a new peak appears. For those materials which do not separate sharply, the heading and tailing of the peaks may be used to actuate the fraction collector. In this case, the rate of peak decay or buildup could be used as the controlling signal. This method would have the advantage afforded by the taking of fraction as a function of changing purity, but a combination of the first method together with the usual volume or time-actuated mechanism of the fraction collector would achieve nearly the same result with much simpler control.

When either the sample or the adsorbent is electrically conducting, the cell consisting of the single block should be used. The thermistors used in this cell are of the glass-enclosed probe type and are inserted through the side of the cell. The probe can be sealed in the block with the usual stuffing box arrangement or by making a liquid-tight seal with epoxy resin or soft solder. Such a thermistor has a much higher heat capacity than the bead type and the recorded peaks tend to be less high. The larger size of this probe does not seem to disrupt the flow pattern of the liquid. The problem of increased heat capacity can be minimized by using a low-gain d-c amplifier prior to recording the signal or by using thermistors of higher resistance.

The use of cells of this and similar types in conjunction with other analytical tools should make a systematic study of liquid-solid chromatographic separation more feasible.

The author is indebted to Miss Nancy Beach for her assistance in the performance of early experiments and to Herbert B. Lowey for his assistance in the design and fabrication of the cells.

(Paper 65C4-77) 